\title{
Exposure to Gambling and Alcohol Marketing in Soccer Matchday Programmes
}

Dr Steve Sharman¹, Ms Catia Alexandra Ferreira², \& Dr Philip W. S. Newall ${ }^{3,4}$

${ }^{1}$ University of East London. School of Psychology, University of East London, Water Lane, Stratford, E15 4LZ, United Kingdom. ORCID - 0000-0001-9816-7981

${ }^{2}$ Anglia Ruskin University. School of Psychology and Sport Science, Anglia Ruskin University, Cambridge Campus, East Road, Cambridge, CB1 1PT, United Kingdom

${ }^{3}$ University of Warwick. Applied Psychology, WMG, University of Warwick, Coventry, CV4 7AL, United Kingdom

${ }^{4}$ Experimental Gambling Research Laboratory, School of Health, Medical and Applied Sciences, CQ University, 120 Spencer St, Melbourne, VIC 3000, Australia

\section{In Press, Journal of Gambling Studies}

Corresponding Author: Steve Sharman (ssharman@uel.ac.uk) +44 (0)20 82234546

Competing interests: SS is currently funded by the Society for the Study of Addiction.

PN was included as a named researcher on a grant funded by GambleAware (2018), and in 2019 received travel and accommodation funding from the Spanish Federation of Rehabilitated Gamblers. CAF has no competing interests to declare. None of the interests declared had any influence on the design of the study, or the collection, analysis, and interpretation of data or in writing the manuscript.

Funding: This study was funded by an internal University of East London QR fund grant. The funding body had no influence in the design of the study, or the collection, analysis, and interpretation of data or in writing the manuscript.

Authors' contributions: CAF and SS were primarily responsible for data extraction and coding. All authors were responsible for data analysis, and manuscript preparation. 


\section{Abstract}

Background: The UK's Premier League and Championship are two of the most well attended soccer leagues worldwide; however, little is known regarding exposure to gambling marketing through the matchday experience. The current study sought to quantify exposure to gambling and alcohol marketing, and responsible gambling messages within matchday programmes.

Methods: Programmes for each team in the English Premier League and Championship were analysed across consecutive matchday weekends, made available to 1,269,404 match-going fans. Direct adverts for, and incidental exposure to, gambling, alcohol, and responsible gambling marketing or messages were coded. Direct adverts were counted, as were absolute counts and percentage of pages with incidental exposure.

Results: Programmes averaged 2.3 direct gambling adverts and 37.8 instances of incidental gambling marketing exposure. Incidental gambling marketing was found on $22.2 \%$ of pages. There was more gambling marketing than either alcohol marketing or responsible gambling messages. This was observed across: number of direct adverts $(p<.001)$, incidents of exposure $(p<.001)$ and the percentage of pages with exposure $(p<.001)$. Teams with gambling shirt sponsors had more incidental marketing exposure, in both absolute count ( $p$ $<.001)$ and percentage of pages $(p<.001)$ but did not have more direct gambling adverts $(p=$ .63). Incidental exposure to gambling marketing was present in $59.0 \%$ of children's specific sections of programmes.

Conclusions. There was greater exposure to gambling marketing in soccer matchday programmes. Gambling marketing was frequently evident in child specific sections of matchday programmes. Attending soccer matches and reading the matchday programme increases exposure to gambling.

Key words: Gambling; Advertising; Marketing; Sponsorship; Pathological gambling; disordered gambling; 
Introduction

The close relationship between potentially addictive products such as alcohol and gambling with sports, and in particular soccer, has been a growing cause for concern. Major soccer organisations including world soccer's governing body FIFA, and international soccer tournaments including the World Cup have alcohol product advertising partners (Purves, Critchlow \& Stead, 2016). A study of the Euro 2016 soccer tournament found an average of 0.65 marketing references to alcohol per broadcast minute in UK broadcasts (Purves, Critchlow, Stead, Adams, \& Brown). Although soccer and alcohol are closely linked at an institutional level, gambling seems more strongly associated with soccer at a club level. For example, across the 2018/2019 season, 9 teams (out of 20) in England's top division, the Premier League, and 17 (out of 24) in the Championship had gambling shirt sponsors. For the upcoming 2019/2020 season, 10 Premier League teams will be sponsored by gambling companies (Davies, 2019). In comparison, no teams in either division had alcohol shirt sponsors. The Premier League is an internationally recognised brand, with an everincreasing global reach (Bunn, Ireland, Minton, Holman, Philpott \& Chambers, 2019); for the 2018/19 season, the cumulative viewing figures totalled over 3.2 billion people ('Premier League global audience', 2019) with record viewing figures reported in both the US and Chinese markets ('Fans watch Premier League', 2019).

Gambling advertising comes in multiple media formats, including TV, online and print media. Since the Gambling Act 2005, the overall incidence of TV gambling advertising in the UK has increased sharply. Within five years of implementation of the 2005 Gambling Act, the overall proportion of gambling advertising on TV has increased to 4.1\% (Ofcom, 2013). Live sport is currently exempt from a 9pm watershed for gambling advertising, in accordance with the 2007 Industry Code for Socially Responsible Advertising, published to coincide with implementation of the 2005 Gambling Act. Consequently, a much higher proportion of gambling adverts can be seen during live sport. Up to 95\% of live soccer coverage featuring at least one gambling advert (Smith, 2017), whilst $17 \%$ of all TV adverts shown during the 2018 soccer World Cup were for gambling (Duncan, 2018). Furthermore, gambling adverts show very clearly how to place a bet and communicate betting terminology, despite being shown at peak times when a significant proportion of the audience will be children (Pitt, Thomas, Bestman, Daube \& Derevensky, 2017).

Following media scrutiny and political pressure, the gambling industry has launched several 'responsible gambling' campaigns, including 'when the fun stops, stop', 'bad betty', and 'bet regret'. However, the effectiveness of these campaigns has been questioned (Newall, Walasek, Singmann \& Ludvig, 2019). Furthermore, in December 2018 the remote gambling association voluntarily agreed to a 'whistle-to-whistle' ban on gambling advertising during live sport, covering the period five minutes before kick-off to five minutes after full-time (Kelner, 2018). However, once in force from August 2019, this ban will do nothing to reduce background gambling brand exposure.

Consistent exposure to gambling brands serves to further normalise gambling within sports culture; Pitt, Thomas, Bestman, Stoneham \& Daube (2016) previously reported that $75 \%$ of children, and $90 \%$ of adults perceive that sports betting was becoming a normal part of 
sport, whilst Hing, Russell, Lamont \& Vitartas (2017) found exposure to gambling marketing to be detrimental to both adult problem gamblers and children, posing a significant impact on at risk and problem gamblers, particularly in-play sports betting adverts. However, it is possible that direct gambling advertising on TV might represent the most visible portion of a wider problem. Gambling brand exposure is evident on TV through numerous shirt, pitchside, and background gambling brand exposures. In one study, incidental exposure to gambling marketing was visible for between 71 and $89 \%$ of screen time on the noncommercial BBC's match-day highlights TV show, Match of the Day (MoTD) (Cassidy \& Ovenden, 2017). Although usually shown first around 10:30pm, MoTD is repeated on Sunday morning, and is then available on BBC iplayer for 30 days, meaning many children will watch, and be exposed to gambling marketing via this medium. Furthermore, with nearly $60 \%$ of the teams across England's top two soccer divisions have gambling brands as their shirt sponsor for the 2018-19 season, it has been suggested that shirt sponsorship could be one factor contributing to $78 \%$ of a sample of British children reporting in a recent study that betting is now a normal part of sport (Djohari, Weston, Cassidy, Wemyss, \& Thomas, 2019).

The purchase of a match-day programme has long been a part of the experience of attending a live soccer match, and shirt sponsors are visible in most pictures of players in a match-day programme. Programmes provide home fans with updates on their team, that day's opposition, and are seen as collectible items by many fans. Encouraging match attendance, meanwhile, has long been an important goal for the governing body for English soccer, the 'Football Association', which prevents any matches from being broadcast live on UK TV at 3pm on Saturdays, to encourage attendance at lower-league non-televised matches. The match-day programme could arguably be an important vehicle for gambling advertising exposure, as our sample of programmes was made available to a total of $1,269,404$ match-going fans. However, no systematic study has as yet attempted to record the incidence of gambling adverts and incidental gambling exposure in match-day soccer programmes.

This paper seeks to quantify the prevalence of gambling adverts and incidental gambling exposure in match-day soccer programmes and compare to the equivalent figures for alcohol and dedicated responsible gambling messages. The study also sought to compare exposure prevalence for teams sponsored by gambling companies, a particularly salient aspect of gambling marketing (Davies, 2018; Hymas, 2019), compared to teams sponsored by other industries. Furthermore, the incidence of gambling exposure in the programmes' dedicated children's sections was also recorded. The following hypotheses were made across all programmes:

It was hypothesised that all programmes will contain more gambling adverts than either alcohol or responsible gambling adverts $(\mathrm{H} 1)$, and that the number of gambling adverts would be higher in the programmes of those teams sponsored by a gambling company than those sponsored by another industry $(\mathrm{H} 2)$. It was also hypothesised that the percentage of pages with incidental exposure $(\mathrm{H} 3)$, and the absolute counts of incidental exposure $(\mathrm{H} 4)$ would be higher for gambling than either alcohol or responsible gambling messages. It was 
hypothesised that the percentage of pages with gambling incidental exposure and the absolute counts of incidental exposure would be higher for teams sponsored by gambling companies than those sponsored by another industry (H5, H6). Finally, it was hypothesised that exposure to gambling, alcohol, and responsible gambling messages would not be evident in children's sections, as there are all adult activities or products ( $\mathrm{H} 7)$.

\section{METHODS}

Data were drawn from the matchday programmes from each of the teams in the English Premier League, and the English Championship across consecutive weekends in October 2018 (19 $19^{\text {th }}-22^{\text {nd }}$ October, and $26^{\text {th }}-29^{\text {th }}$ October). Programmes were obtained from multiple sources including footballprogrammes.net, Ebay.com, and from some clubs directly. In total, 44 programmes were obtained, one for a home game for each team in the Premier League and the Championship. Each team also features once as an away side in the programmes. These programmes cost around an average of $£ 3.25\left(S D=2.8, M^{\mathrm{in}}=£ 2, \mathrm{M}^{\mathrm{ax}}=£ 4\right)$, and were between 40 and 116 colour pages in length $(M=83.2, S D=13.3)$.

Adverts and incidental exposure were coded according to 'Type' (gambling, alcohol, and responsible gambling). Adverts were only coded as a single instance, regardless of the number of times the brands logo appeared on the advert. Incidental exposure was classified as clear brand placement, encompassing all exposure that was not clearly a dedicated advert (e.g. branding as a shirt sponsor), where the majority of words or numbers making up the brand's name was clearly visible. A specific visibility proportion threshold of the characters composing the brand's name was not utilised, due to the brevity of some brand's names. Instances where the brand's colour scheme was apparent, but the actual name could not be read, were not counted. The following data was collated from each programme:

- Direct Adverts: Adverts were recorded as a single exposure regardless of how many times the advertiser's logo appeared in the advert.

- Incidental Exposure: Absolute Counts. In accordance with the approach refined by Lindsay et al (2013), exposure to the same brand that was apparent simultaneously, e.g. the same shirt sponsor appearing in multiple photographs on the same page, were counted as separate instances of incidental exposure. The cumulative total of each instance of marketing exposure is referred to subsequently as the absolute count.

- Incidental Exposure: Percentage of pages. Binary yes / no data for whether each programme pages containing any gambling, alcohol or responsible gambling marketing were recorded, allowing calculation of the overall percentage of pages in each programme that contained each type of marketing exposure. Responsible gambling messages at the bottom of gambling adverts were coded as incidental exposure, as were clear views of responsible gambling patches on the sleeves of teams in the championship.

- Incidental Exposure: Children's sections. Absolute counts of incidental exposure in children's sections of programmes were coded per programme section, as individual pages were less well defined than in the overall programme. 
Inter-rater reliability was computed by dual-coding $10 \%$ of the sample of programmes using an Intraclass Correlation Coefficient (ICC). Analysis used a single measure, mixed, two-way model of ICC based on absolute agreement (Hallgren, 2012). As shown in Table 1, inter-rater agreement was high, with an ICC varying between 0.86 and 1, indicating an excellent level of agreement (Cicchetti, 1994).

\section{*** Insert table 1 here $* * *$}

Analysis was performed in SPSS 23. ANOVA models were run to ascertain the main effect of predictor variables 'Type' (Gambling, Alcohol, Responsible Gambling) on outcome variable 'Frequency', and to ascertain the main effect of predictor variables 'Type' and 'Group' (Gambling sponsored, non-gambling sponsored), on outcome variable 'Frequency'. An alpha level of .05 was used in ANOVA models unless sphericity was violated, whereby Greenhouse-Geisser corrections are reported. Number of pages was included as a covariate in a separate analysis; the main effects remained significant, therefore original ANOVA models are reported. Although data for responsible gambling exposure was not normally distributed, ANOVA models were preferred to the non-parametric Kruskal-Wallis test due to the reported robustness of the $F$ statistic when data is non-normally distributed (Blanca, Alarcón, Arnau, Bono, \& Bendayan, 2017; Ferreira, Rocha, Mequelino, 2012). Post-hoc pairwise comparisons were run where appropriate. Bonferroni corrections for multiple comparisons were applied. Eta squared is reported as a measure of effect size. Standard $t$ tests were used for between groups comparisons on ratio data, and Chi-squared analysis was used for categorical data. The dataset generated and/or analysed during the current study is available in the Open Science Framework repository: https://osf.io/bxrvs (Sharman, Ferreira \& Newall, 2019).

Results

Adverts

The ANOVA model for number of adverts indicated a significant main effect of Type ( $F(1.47$, $\left.63.3)=65.5, p<.001, \eta^{2}=.60\right)$. There was an average of 2.3 gambling adverts perprogramme, $(M=2.3, S D=1.4)$ a significantly greater number than the 0.61 alcohol adverts $(S D=.7),(t(43)=7.26, \mathrm{p}<.001)$, and 0.1 responsible gambling adverts per-programme (SD $=.4),(t(43)=9.73, p<.001)$. Alcohol adverts were more prevalent than Responsible gambling adverts $(t(43)=4.04, p<.001)$.

There were an average of 2.1 gambling adverts in programmes where the home team was sponsored by a gambling company $(S D=1.6)$, which did not significantly differ from the average of 2.4 adverts $(S D=1.3)$ where the home team was sponsored by a company from a different industry $(t(42)=.48, p=.63)$.

Incidental Exposure

The ANOVA model for the percentage of pages containing incidental exposure indicated a significant main effect of Type $\left(F(1.29,55.26)=100.91, p<.001, \eta^{2}=.70\right)$. On average, $22.2 \%$ of pages had incidental gambling exposure $\left(S D=12.3, \mathrm{M}^{\mathrm{in}}=4.8, \mathrm{M}^{\mathrm{ax}}=51.2\right)$, significantly greater than the average of $2.8 \%$ of pages with alcohol incidental exposure (SD 
$\left.=2.8, \mathrm{M}^{\mathrm{in}}=0, \mathrm{M}^{\mathrm{ax}}=14.3 ; t(43)=10.01, \mathrm{p}<.001\right)$, and $3.3 \%$ of pages with responsible gambling incidental exposure $\left(S D=4.2, \mathrm{M}^{\mathrm{in}}=0, \mathrm{M}^{\mathrm{ax}}=15 ; t(43)=11.27, \mathrm{p}<.001\right)$.

The ANOVA model for the absolute count of instances of incidental exposure indicated a significant main effect of Type $\left(F(1.1,47.48)=64.96, p<.001, \eta^{2}=.60\right)$. Each programme averaged 37.8 counts for gambling incidental exposure $\left(S D=27.4, M^{\text {in }}=6, M^{\text {ax }}=98\right)$, significantly higher than the 3.8 counts for alcohol $\left(S D=4.1, M^{\text {in }}=0, M^{\text {ax }}=19 ; t(43)=7.96, p\right.$ $<.001)$, and 4.7 counts for responsible gambling $\left(S D=5.9, M^{\text {in }}=0, M^{\text {ax }}=31 ; t(43)=8.5, p\right.$ $<.001)$.

Programmes for home teams with a gambling sponsor had more incidental gambling exposure than teams sponsored by other industries. Exposure occurred on $30.8 \%$ of all pages $(S D=8.7$ ) where the home team was sponsored by a gambling company, significantly more than the $10.8 \%$ for programmes where the home team was sponsored by a company from a different industry $(S D=4.8 ; t(38.8)=9.74, p<.001)$. There were 57.3 counts of incidental exposure $(S D=20.0)$ when the home team was sponsored by a gambling company, significantly higher than the 12.2 counts $(S D=6.0)$ where the team was sponsored by a company from a different industry $(t(29.56)=10.6, p<.001)$.

Incidental Exposure - Children's Sections

Of the 44 programmes included in the study, $39(88.6 \%)$ had a dedicated children's section of the programme. Subsequent analysis is performed on these 39 programmes. There was no incidental exposure to responsible gambling messages. Incidental gambling exposure was present in $59.0 \%$ of children's specific sections of programmes, significantly higher than the $7.7 \%$ for alcohol incidental exposure $\left(\chi^{2}(1)=58.4, p<.001\right)$. Children's sections averaged 1.5 incidents of gambling exposure per section, $(S D=2.0)$, significantly more than the $0.08(S D=$ .3 ) average incidents of alcohol exposure $(t(38)=4.2, p=.001)$.

\section{Discussion}

The current study sought to compare prevalence of adverts and incidental exposure to gambling, alcohol and responsible gambling marketing. Overall, the programmes contained more gambling adverts (2.3) than responsible gambling (0.1) or alcohol adverts (0.6). There was no difference in the frequency of gambling adverts between teams sponsored by gambling companies and teams sponsored by other industries. For incidental exposure, overall a higher percentage of pages contained gambling exposure (22.2\%) than responsible gambling (3.3\%) or alcohol exposure (2.8\%). In programmes where the home team was sponsored by a gambling company, the percentage of pages with incidental exposure to gambling rose to $30.8 \%$. The average absolute count for incidental exposure was higher per programme for gambling $(37.8 \%)$ than for responsible gambling $(4.7 \%)$ or alcohol $(3.8 \%)$. When the home team was sponsored by a gambling company, the average absolute count of incidental exposure rose to 57.3 exposures per programme. Of the programmes that had dedicated child sections (88.6\%) 59.0\% had gambling incidental exposure, compared to 7.7 for alcohol. Overall, the results further highlight the closeness of the relationship between football and gambling, with both the percentage of pages per programme and the absolute counts of gambling exposure significantly higher than alcohol or responsible gambling 
exposure. Of particular concern is the identification of significant exposure to gambling marketing in the dedicated child sections of matchday programmes.

\section{Impact}

Increased, repeated exposure to gambling marketing through different mediums, specifically a matchday programme, increases brand recognition. Brand recognition is thought to be fundamental to gambling company's social media and online marketing strategies, which can contain much more specific, targeted messaging (Gainsbury, King, Hing, \& Delfabbro, 2015). In addition to exposure in the matchday programme, increased brand recognition as part of the matchday experience is supplemented by additional exposure, via pitch side advertising boards, shirt sponsors (as worn by players and fans), and even in some cases, half time entertainment.

The present study found that a large number of child specific programme sections contained exposure to gambling marketing. The impact of exposure to gambling marketing on children is not insignificant; using an implicit recall task, an Australian study found that $77 \%$ of children were able to identify at least one NRL / AFL shirt sponsor, with better recall for more popular sports (Bestman, Thomas, Randle, \& Thomas, 2015). Using a similar task, a further study reported that over $75 \%$ of children (aged 8-16) could correctly recall the name of at least one sports betting brand, and over $26 \%$ could identify 4 or more brands (Thomas, Pitt, Bestman, Randle, Daube \& Pettigrew (2016). A recent British study supported this finding, reporting that $63 \%$ of children sampled could correctly match a shirt sponsor with the corresponding team, whilst $20 \%$ of children matched a gambling logo to the corresponding team (Dhojari et al, 2019), highlighting the impact that repeated brand exposure, such as that provided in a matchday programme, can have.

\section{Legislative Response}

Whilst gambling companies claim to take Corporate Social Responsibility (CSR) seriously, some gambling company staff are sceptical regarding the real-world impact of industry-led CSR initiatives (Pratten \& Walton, 2008). Bookmakers had previously offered to restrict advertising to one advert per ad-break during live sporting events, whilst recently one large UK bookmaker has called for a whistle-to-whistle ban and has called for an end to shirt sponsorship. However, the bookmaker in question do not directly sponsor any top-level teams in England, only 2 third tier teams through a subsidiary company, therefore such a course of action would impact rivals significantly more than the bookmaker in question. Furthermore, by directing legislative attention towards TV advertising, there is less attention paid to online marketing which is tailored to and targeted at specific individuals (Gainsbury et al, 2015). Many non-targeted individuals may be unaware of the scale of online gambling marketing, even though gambling operators are currently spending significantly more money on online marketing than on TV gambling advertising (GambleAware, 2018). Quantifying the extent to which gambling advertising is targeted toward certain individuals, rather than others, is an important current issue in gambling advertising research (Newall et al, 2019). 
Recent legislative moves have been made to combat the increase in gambling marketing. In 2018, the Committees of Advertising Practice (CAP) implemented a new code which, in part, focused on eliminating advertising content that targeted individual susceptibilities such as impulsivity, risk perception, and financial motives (Advertising Standards Agency, 2018), although this code's effect on advertising content has been questioned (Newall, Thobani, Walasek \& Meyer, 2019). This was followed in 2019 by the introduction of a new code designed to protect children from 'irresponsible' gambling adverts; one of the key standards was to 'prohibit the use in gambling ads of sportspersons, celebrities or other characters who are or appear to be under 25 (Advertising Standards Agency, 2019). The CAP code appears to only apply to gambling adverts, as many of the players wearing the team jersey carrying a gambling company logo, thus providing incidental exposure to gambling marketing are celebrity sportspersons who are under 25 , in direct contravention of the code.

\section{Limitations}

The current analysis was taken from a single programme for each team in the top two divisions of the English Football pyramid. This presents two limitations; first, the data presented provides a snapshot across two weeks of matches. It is unknown if the frequency of adverts and incidental exposure to gambling and alcohol marketing would remain consistent across the entirety of a season. Second, as data was only collected from programmes from teams in the top two divisions, it is unknown if this pattern is repeated across all divisions. Furthermore, the current study only assessed gambling marketing exposure in the paper form of the matchday programmes; thus, instances of exposure are unknown through online communication, such as the online version of the matchday programme, or matchday activity on club's social media feeds. Future studies could monitor both offline and online gambling marketing exposure. Additionally, this study only sought to measure prevalence of gambling marketing exposure, therefore the content of adverts was not analysed. Finally, although the current study is the first to quantify and compare instances of gambling and alcohol marketing in matchday programmes, little is known regarding the impact of this exposure on either attitudes towards gambling, or gambling behaviour in football supporters of all ages. Future research should seek to measure the impact of consistent exposure.

\section{Conclusions}

Policy makers are increasingly aware of research concerning the impact of gambling TV advertising; however, TV advertising is perhaps the most visible tip of the gambling marketing iceberg. The current research demonstrates that in just one traditional format, the matchday programme available at most English Premier League and Championship matches, fans are exposed to gambling marketing at a significantly higher rate than alcohol marketing, or responsible gambling messages. Incidental exposure comes predominantly in the form of pictures of players in the team shirt where the team is sponsored by a gambling company. Frequent exposure normalises gambling as part of the matchday experience, even for children attending matches, as demonstrated by gambling marketing being present in child specific sections of the programmes. The increase in shirt sponsoring by gambling 
companies increases incidental marketing exposure. Whilst this pattern continues, football clubs and programme producers must be more aware of the content to which all fans, and in particular young fans, are exposed. Additionally, policy makers and legislators must be aware of the multitude of avenues via which exposure to gambling marketing can be experienced. 


\section{References}

Advertising Standards Agency (2018) 'Tougher standards on gambling advertising announced' retrieved from https://www.asa.org.uk/news/tougher-standards-ongambling-advertising-announced.html $5^{\text {th }}$ June, 2019.

Advertising Standards Agency (2019)'New standards protecting children from irresponsible gambling ads' retrieved from https://www.asa.org.uk/news/new-standardsprotecting-children-from-irresponsible-gambling-ads.html $5^{\text {th }}$ June, 2019

Bestman, A., Thomas, S. L., Randle, M., \& Thomas, S. D. (2015). Children's implicit recall of junk food, alcohol and gambling sponsorship in Australian sport. BMC public health, 15(1), 1022.

Blanca, M., Alarcón, R., Arnau, J., Bono, R., \& Bendayan, R. (2017). Non-normal data: Is ANOVA still a valid option?. Psicothema, 29(4), 552-557.

Bunn, C., Ireland, R., Minton, J., Holman, D., Philpott, M., \& Chambers, S. (2019). Shirt sponsorship by gambling companies in the English and Scottish Premier Leagues: global reach and public health concerns. Soccer \& Society, 20(6), 824-835.

Cassidy, R., \& Ovenden, N. (2017). Frequency, duration and medium of advertisements for gambling and other risky products in commercial and public service broadcasts of English Premier League football.

Cicchetti, D. V. (1994). Guidelines, criteria, and rules of thumb for evaluating normed and standardized assessment instruments in psychology. Psychological assessment, 6(4), 284.

Davies, R. (2018) 'Laboour pledges ban on TV gambling during live sports' retrieved from https://www.theguardian.com/sport/2018/sep/20/labour-pledges-ban-on-tvgambling-adverts-during-live-sports $5^{\text {th }}$ June 2019

Davies, R. (2019) 'Half of Premier League clubs to have gambling sponsors for 2019-20 season' retrieved from https://www.theguardian.com/football/2019/jul/19/half-ofpremier-league-clubs-to-have-gambling-sponsors-for-201920 $23^{\text {rd }}$ July 2019

Djohari, N., Weston, G., Cassidy, R., Wemyss, M., \& Thomas, S. (2019). Recall and awareness of gambling advertising and sponsorship in sport in the UK: a study of young people and adults. Harm reduction journal, 16(1), 24.

Duncan, P., Davies, R., \& Sweney. (2018) 'Children 'bombarded'with betting adverts during world cup'. Retrieved from https://www.theguardian.com/media/2018/jul/15/children-bombarded-withbetting-adverts-during-world-cup $5^{\text {th }}$ Jun2019

'Fans watch Premier League in record numbers' (2019) Retrieved from https://www.premierleague.com/news/1225124. $23^{\text {rd }}$ July 2019. 
Ferreira, E. B., Rocha, M. C., \& Mequelino, D. B. (2012). Monte Carlo evaluation of the ANOVA's F and Kruskal-Wallis tests under binomial distribution. Sigmae, 1(1), 126139.

Gainsbury, S. M., King, D. L., Hing, N., \& Delfabbro, P. (2015). Social media marketing and gambling: An interview study of gambling operators in Australia. International Gambling Studies, 15(3), 377-393.

GambleAware. (2018) https://about.gambleaware.org/media/1853/2018-11-24-rp-ga-gbmarketing-spend-infographic-final.pdf. Accessed $8^{\text {th }}$ July 2019.

Hallgren, K. A. (2012). Computing inter-rater reliability for observational data: an overview and tutorial. Tutorials in quantitative methods for psychology, 8(1), 23.

Hing, N., Russell, A. M. T., Lamont, M., \& Vitartas, P. (2017). Bet anywhere, anytime: An analysis of Internet sports bettors' responses to gambling promotions during sports broadcasts by problem gambling severity. Journal of Gambling Studies, 33(4), 10511065.

Hymas, C. (2019) 'Ban gambling firm logos on football club shirts say church of England' Retrieved from https://www.telegraph.co.uk/politics/2019/02/01/ban-gamblingfirm-logos-football-clubs-shirts-says-church-england/ $5^{\text {th }}$ June 2019.

Kelner, M. (2018) 'Ban on in-play tv adverts is denied as betting stocks lose' Retrieved from https://news.sky.com/story/ban-on-in-play-tv-gambling-adverts-is-denied-asbetting-stocks-lose-11573019. 2018. $5^{\text {th }}$ June 2019

Lindsay, S., Thomas, S., Lewis, S., Westberg, K., Moodie, R., \& Jones, S. (2013). Eat, drink and gamble: marketing messages about 'risky' products in an Australian major sporting series. BMC public health, 13(1), 719.

Newall, P. W. S., Moodie, C., Reith, G., Stead, M., Critchlow, N., Morgan, A., \& Dobbie, F. (2019). Gambling marketing from 2014 to 2018: A literature review. Current Addiction Reports, 6(2), 49-56.

Newall, P. W. S., Thobhani, A., Walasek, L., \& Meyer, C. (2019). Live-odds gambling advertising and consumer protection. PloS one, 14(6), e0216876.

Newall P. W. S., Walasek L., Singmann H., Ludvig E. A. (2019) Testing a gambling warning label's effect on behavior [Internet]. PsyArXiv; Available from: psyarxiv.com/dxfkj

Ofcom (2013) retrieved from

https://www.ofcom.org.uk/ data/assets/pdf file/0026/53387/trends in ad activi ty gambling.pdf. $5^{\text {th }}$ June 2019

Pitt, H., Thomas, S. L., Bestman, A., Daube, M., \& Derevensky, J. (2017). What do children observe and learn from televised sports betting advertisements? A qualitative study among Australian children. Australian and New Zealand journal of public health, 41(6), 604-610. 
Pitt, H., Thomas, S. L., Bestman, A., Stoneham, M., \& Daube, M. (2016). “It's just everywhere!" Children and parents discuss the marketing of sports wagering in Australia. Australian and New Zealand journal of public health, 40(5), 480-486.

Pratten, J. D., \& Walton, S. (2008). Policy and reality: Corporate social responsibility in the UK gambling industry. In Corporate Responsibility Research Conference.

Purves, R. I., Critchlow, N., \& Stead, M. (2017). Foul play. Alcohol marketing during UEFA Euro 2016.

Purves, R., Critchlow, N., Stead, M., Adams, J., \& Brown, K. (2017). Alcohol marketing during the UEFA EURO 2016 football tournament: a frequency analysis. International journal of environmental research and public health, 14(7), 704.

'Premier League global audience on the rise' (2019) retrieved from https://www.premierleague.com/news/1280062, 23 $3^{\text {rd }}$ July 2019.

Sharman S, Ferreira CA, \& Newall PWS. (2019) Exposure to Gambling and Alcohol Marketing in Soccer Match day Programmes dataset. Open Science Framework. https://osf.io/bxrvs

Smith, S. (2017) 'Gambling adverts feature in 95pc of all televised football matches, researchers find'. Retrieved https://www.telegraph.co.uk/business/2017/10/23/gambling-adverts-feature-95pctelevised-football-matches-researchers/25 $25^{\text {th }}$ April 2019.

Thomas, S., Pitt, H., Bestman, A., Randle, M., Daube, M., \& Pettigrew, S. (2016). Child and parent recall of gambling sponsorship in Australian sport. Victoria: Victorian Responsible Gambling Foundation, 1. 
Tables

Table 1 - Inter-relater reliability correlations

\begin{tabular}{|c|c|c|}
\hline Variable & ICC & $95 \% \mathrm{Cl}$ \\
\hline Does the page contain a gambling advert? & 1 & - \\
\hline Does the page contain an alcohol advert? & 1 & - \\
\hline $\begin{array}{l}\text { Does the page contain a responsible gambling } \\
\text { advert? }\end{array}$ & 1 & - \\
\hline $\begin{array}{l}\text { Does the page have incidental exposure to } \\
\text { gambling? }\end{array}$ & 0.92 & $.91-.93$ \\
\hline $\begin{array}{l}\text { Does the page have incidental exposure } \\
\text { to alcohol? }\end{array}$ & 0.97 & $.97-.98$ \\
\hline $\begin{array}{l}\text { Does the page have incidental exposure } \\
\text { to responsible gambling? }\end{array}$ & 1 & - \\
\hline $\begin{array}{l}\text { How many instances of incidental exposure to } \\
\text { gambling are on the page? }\end{array}$ & 0.97 & $.96-.98$ \\
\hline $\begin{array}{l}\text { How many instances of incidental exposure } \\
\text { to alcohol are on the page? }\end{array}$ & 0.86 & $.83-.88$ \\
\hline $\begin{array}{l}\text { How many instances of incidental exposure } \\
\text { to responsible gambling are on the page?* }\end{array}$ & - & - \\
\hline
\end{tabular}

